\title{
The effect of medical illness related depression on frailty in elderly subjects with heart failure
}

Clinical Interventions in Aging

31 August 2015

Number of times this article has been viewed

\section{Yildiray Topcu \\ Fatih Tufan \\ Gulistan Bahat \\ M Akif Karan}

Department of Geriatrics, Istanbul School of Medicine, Istanbul University, Istanbul, Turkey
Correspondence: Yildiray Topcu Department of Geriatrics, Istanbul School of Medicine, Istanbul University, P.B. 34093, Sehremini, Istanbul, Turkiye Email dr.ytopcu@hotmail.com

\section{Dear editor}

We read the recently published and well-designed study of Uchmanowicz et al which suggests that multidimensional assessment of the frailty syndrome (FS) in subjects with heart failure (HF) is very important. ${ }^{1}$ The authors investigated the association between the dimensions of FS and self-care ability in elderly chronic HF patients. Their findings indicate that only social components of frailty adversely affect the ability to self-care. Their study is especially important regarding two aspects. Firstly, there are limited studies regarding FS in elderly HF patients. Secondly, most commonly used frailty instruments focus on physical components of frailty and overlook psychological and social components. The Tilburg Frailty Indicator (TFI) has the potential to detect psychological and social components of frailty.

We have a few comments about this study. Firstly, although the TFI has a 4-item psychological domain, it is very important to perform a detailed assessment regarding depression in these subjects. Cardiac disease and arthritis are among the most common predisposing factors underlying medical illness related depression. ${ }^{2}$ We wonder if the authors excluded subjects with minor or major depression, because they mentioned a general exclusion criterion of psychiatric disorders. Later life depression is different from younger onset depression in terms of symptoms. Somatic complaints and fatigue are more commonly seen in these subjects. It is also important because it may even complicate accurate functional classification of HF. Depression may be found to be very common when subjects with $\mathrm{HF}$ are screened for it. ${ }^{3}$ In clinical practice, symptoms of depression are generally overlooked. Although the physical and social items of the TFI were responded to by almost all of the participants, this is not the case for most of the items (19-21) of the psychological component, in which the response rate seems to be rather low. We wonder how the authors interpret the lower response rate for these items and the potential effects of the lower response rate.

Secondly, the authors did not find a significant correlation between New York Heart Association class and social components of TFI. Although social support would be especially important in subjects with New York Heart Association class IV HF, there are only two (1.82\%) patients in this functional class in the study. Another point is that, we generally see patients with features of frailty after 70-75 years and the study population in the current study is relatively younger (enrollment $>60$ years, mean age 66 years) and may result in a lower rate of frailty in this study. These might have influenced the results and may be considered as a limitation.

Finally, there are no results regarding regression analysis which the authors mentioned in the methods section. 


\section{Disclosure}

The authors have no conflicts of interest to disclose.

\section{References}

1. Uchmanowicz I, Wleklik M, Gobbens RJ. Frailty syndrome and self-care ability in elderly patients with heart failure. Clin Interv Aging. 2015; 10:871-877.
2. Bisschop MI, Kriegsman DM, Deeg DJ, Beekman AT, van Tilburg W. The longitudinal relation between chronic diseases and depression in older persons in the community: the Longitudinal Aging Study Amsterdam. J Clin Epidemiol. 2004;57(2):187-194.

3. Nasir U, Shahid H, Shabbir MO. Sleep quality and depression in hospitalized congestive heart failure patients. J Pak Med Assoc. 2015;65(3): 264-269. 


\section{Authors' reply}

Izabella Uchmanowicz'

Marta Wleklik'

Robbert JJ Gobbens ${ }^{2,3}$

'Department of Clinical Nursing, Wrocław Medical University, Wrocław, Poland; ${ }^{2}$ Faculty of Health, Sports and Social

Work, Inholland University of Applied Sciences, Amsterdam, the Netherlands; ${ }^{3}$ Zonnehuisgroep Amstelland, Amstelveen, the Netherlands

Correspondence: Izabella Uchmanowicz

Department of Clinical Nursing, Wrocław Medical University, ul Bartla

$5,5|-6| 8$ Wrocław, Poland

$\mathrm{Tel}+48$ 7| $784 \quad 824$

Fax +48 7I 3459324

Email izabella.uchmanowicz@umed.wroc.pl

\section{Dear editor}

In response to the letter from Topcu et al, we would like to thank them first of all for their interest in our paper "Frailty syndrome and self-care ability in elderly patients with heart failure" and their in-depth analysis.

The authors of the letter pointed to a very important issue - depression in elderly patients with heart failure (HF). We appreciate the significance of the issue. This is due to the fact that HF frequently co-occurs with depression, which may develop at any stage of the illness, in response to diagnosis, aggravation or being informed of poor prognosis. There is evidence of common pathophysiological pathways for the two conditions, including neuro-hormonal stimulation, rhythm disorders, inflammation, and hypercoagulability. ${ }^{2}$ Depression has a documented negative effect on the quality of life and prognosis in the HF population. ${ }^{3}$ Regardless of whether it is a new episode, a chronic condition or remission, depression portends a more serious HF course and increased death risk. ${ }^{3,4}$ Despite the proven correlation between depression and poor prognosis, it has not been decisively concluded whether its treatment may have a positive influence on the course of HF. The unsatisfactory level of depression diagnosis and treatment in the HF population must be emphasized, which is mainly due to diagnostic difficulties resulting from the similar clinical presentation of both conditions.

Another issue, pointed out by Topcu et al regarding psychiatric disorders, constituting exclusion criteria in our study, were based on the patients' histories: schizophrenia, current suicide ideation, substance dependence, drinking problems, bipolar disorder, psychosis or receiving specialty mental health treatment.

In another study by Uchmanowicz et al, ${ }^{5}$ we evaluated the correlation of the Tilburg Frailty Indicator (TFI) and its domains (mental and physical) - with other research tools, including the
Mini Mental State Examination, Activities of Daily Living, Instrumental Activities of Daily Living, and the Hospital Anxiety and Depression Scale, commonly used in comprehensive geriatric assessment. The results of the TFI were consistent with the results of the other scales (Activities of Daily Living, Instrumental Activities of Daily Living, Mini Mental State Examination, and Hospital Anxiety and Depression Scale), which means that the TFI may be used for preliminary assessment of depression symptoms in elderly patients. ${ }^{5}$

In our study on frailty and self-care, the mean psychological domain score was $2.13 \pm 1.07$ points, which we believe is not very low. ${ }^{1}$ In the studied group, frailty was found in $75 \%$ of the patients, and self-care capabilities were scored at 27.65 7.13. By means of comparison, in the FRAIL-HF study, using the European Heart Failure Self-Care Behaviour Scale questionnaire, frailty was found in $70.2 \%$ of the patients and self-care capabilities were scored at $29.35 \pm 5.5$ points. ${ }^{1,6}$ The authors of the letter indicated that the level of frailty found in our study was low - while we would consider it rather high. With regard to New York Heart Association (NYHA) classes, most patients (53\%) were classified as having NYHA class II functional status, 35\% were classified within NYHA class III, 11\% were class I, and only $2 \%$ were class IV. ${ }^{1}$ We agree with Topcu et al that the low percentage of patients within NYHA class IV might have influenced the results.

In our study, we included patients aged 60 and over, based on the World Health Organization definition, classifying 60+ individuals as elderly - however, American classifications do, in fact, place the transition point between the mature and old ages at 65 years. ${ }^{7}$ Gerontologists introduce further subdivisions in this period of life, based on changes in biological and clinical factors - the advanced age between 60 and 74, the old age between 75 and 89 , and longevity at 90 and over. We believe that with regard to a population of patients with cardiovascular conditions, this inclusion criterion is optimum.

In our opinion, frailty assessment, including depression assessment, in elderly patients is very important, as for those patients, early stages of HF may exhibit diverse clinical presentations. These include: depression, insomnia, palpitations, and coughing. ${ }^{8}$ Therefore, a special approach to their treatment is required, with more attention paid to geriatric conditions, such as poor mobility, multiple disabilities, cognitive impairment, and frailty.

\section{Disclosure}

The authors have no conflicts of interest to disclose. 


\section{References}

1. Uchmanowicz I, Wleklik M, Gobbens RJ. Frailty syndrome and selfcare ability in elderly patients with heart failure. Clin Interv Aging. 2015;10:871-877.

2. McMurray JJ, Adamopoulos S, Anker SD, et al. ESC Guidelines for the diagnosis and treatment of acute and chronic heart failure 2012: The Task Force for the Diagnosis and Treatment of Acute and Chronic Heart Failure 2012 of the European Society of Cardiology. Developed in collaboration with the Heart Failure Association (HFA) of the ESC. Eur Heart J. 2012;33(14):1787-1847.

3. Krishnan KR, Delong M, Kraemer H, et al. Comorbidity of depression with other medical diseases in the elderly. Biol Psychiatry. 2002;52(6): 559-588.

4. Nicholson A, Kuper H, Hemingway H. Depression as an aetiologic and prognostic factor in coronary heart disease: a meta-analysis of 6362 events among 146,583 participants in 54 observational studies. Eur Heart $J$. 2006;27(23):2763-2774.
5. Uchmanowicz I, Lisiak M, Wontor R, Łoboz-Grudzień K. Frailty in patients with acute coronary syndrome: comparison between tools for comprehensive geriatric assessment and the Tilburg Frailty Indicator. Clin Interv Aging. 2015;10:521-529.

6. Vidan TM, Sanchez E, Fernandez-Aviles F, et al. FRAIL-HF, a study to evaluate the clinical complexity of heart failure in nondependent older patients: rationale, methods and baseline characteristics. Clin Cardiol. 2014;37(12):725-732.

7. World Health Organization [homepage on the Internet]. Definition of an older or elderly person. WHO; 2015. Available from: http://www.who. int/healthinfo/survey/ageingdefnolder/en/. Accessed August 12, 2015.

8. Gottlieb SS, Kop WJ, Ellis SJ, et al. Relation of depression to severity of illness in heart failure (from Heart Failure And a Controlled Trial Investigating Outcomes of Exercise Training [HF-ACTION]). Am J Cardiol. 2009;103(9):1285-1289.

Dove Medical Press encourages responsible, free and frank academic debate. The content of the Clinical Interventions in Aging 'letters to the editor' section does not necessarily represent the views of Dove Medical Press, its officers, agents, employees, related entities or the Clinical Interventions in Aging editors. While all reasonable steps have been taken to confirm the content of each letter, Dove Medical Press accepts no liability in respect of the content of any letter, nor is it responsible for the content and accuracy of any letter to the editor.

\section{Publish your work in this journal}

Clinical Interventions in Aging is an international, peer-reviewed journal focusing on evidence-based reports on the value or lack thereof of treatments intended to prevent or delay the onset of maladaptive correlates of aging in human beings. This journal is indexed on PubMed Central, MedLine,
CAS, Scopus and the Elsevier Bibliographic databases. The manuscript management system is completely online and includes a very quick and fair peer-review system, which is all easy to use. Visit http://www.dovepress. $\mathrm{com} /$ testimonials.php to read real quotes from published authors. 